\title{
INDUÇÃO DA FERMENTAÇÃO MALOLÁCTICA EM VINHO TINTO COM A CULTURA LÁCTICA VINIFLORA OENOS ${ }^{1}$
}

\author{
INDUCTION OF MALOLACTIC FERMENTATION IN RED WINE WITH THE \\ STARTER CULTURE VINIFLORA OENOS
}

\author{
Larissa Dias de Avila ${ }^{2}$ Carlos Eugenio Daudt ${ }^{3}$
}

\section{RESUMO}

A fermentação maloláctica é responsável pela redução da acidez total, muitas vezes elevada em vinhos tintos jovens, ao mesmo tempo que proporciona maior estabilidade biológica e complexidade de aroma e sabor. No Estado do Rio Grande do Sul, a fermentação maloláctica se torna uma necessidade devido a freqüente elevada acidez das uvas, no entanto a indução por inoculação bacteriana não tem sido prática comum. Este trabalho teve como objetivo principal avaliar o comportamento de uma cultura láctica na indução da fermentação maloláctica, em relação as bactérias nativas. Um mosto da Vitis vinífera Cabernet Sauvignon foi vinificado e inoculado com a cultura comercial de Leuconostoc oenos, Viniflora Oenos, em diferentes níveis de açúcar residual: 34,1 - 13,8 - 1,7 e 1,5g/l. As inoculações, com duas repetições, foram comparadas com a fermentação maloláctica espontânea (controle). A degradação do ácido málico foi acompanhada através de cromatografia em papel. Os ácidos orgânicos foram determinados através de cromatografia líquida de alta eficiência. Foram também analisados os açúcares redutores (AR), ?Brix, $\mathrm{pH}$, acidez total e álcool. Os vinhos inoculados no estádio $34,1 \mathrm{~g} / \mathrm{l}$ AR fermentaram em 14 dias, enquanto os controles levaram em média 28,5 dias. Nos estádios com 13,8 e 1,7g/l AR, Viniflora Oenos completou a degradação do ácido málico em torno de 13 e 11 dias, enquanto os controles levaram 20,5 e 16,5 dias, respectivamente. No estádio 1,5g/l AR, os vinhos inoculados e os controles não demonstraram diferença significativa e fermentaram entre 8 e 10 dias. Viniflora Oenos completou a fermentação maloláctica em menos tempo que o controle, demostrando que a inoculação pode ser realizada antes do término da fermentação alcoólica com bons resultados. $\mathrm{Na}$ maioria dos tratamentos, não houve diferença significativa na produção de ácido acético entre a cultura e o controle. $O$ comportamento dos ácidos málico, acético, láctico, pirúvico e tartárico foi demonstrado.

Palavras-chave: ácidos orgânicos, cultura láctica, Leuconostoc oenos, mosto, vinho.

\section{SUMMARY}

Malolactic fermentation is responsible for the reduction of the total acidity, which usually is too high in young red wines. This fermentation provides a higher biological stability and higher complexity of aroma and flavor. In the State of Rio Grande do Sul, malolactic fermentation becomes a necessity because frequently grapes have high acidity and the induction by bacterial inoculation has not been a common practice. This work had as a main aim to evaluate the lactic culture behavior in the induction of malolactic fermentation in relation to the wild bacteria. A must of Cabernet Sauvignon Vitis vinifera was fermented and inoculated with the commercial culture of Leuconostoc oenos, Viniflora Oenos in several residual sugar levels: $34.1-13.8-1.7$ and $1.5 \mathrm{~g} / \mathrm{l}$. The inoculations, in duplicate, were compared with spontaneous malolactic fermentation (control). Degradation of malic acid was monitored through paper chromatography. Organic acids were determinated by high performance liquid chromatography (HPLC). Reducing sugars (RS), ${ }^{\circ}$ Brix, $p H$, total acidity and alcohol were also analysed. The inoculated wine in the $34.1 \mathrm{~g} / \mathrm{l}$ RS stage fermented in 14 days, while the control took 28.5 days in average. In the 13.8 and $1.7 \mathrm{~g} /$ lRS stages, Viniflora Oenos completed the malic acid degradation around 13 and 11 days, while the controls took 20.5 and 16.5 days, respectively. In the $1.5 \mathrm{~g} / \mathrm{l} \mathrm{RS}$ stage, the inoculated wines and the controls did not demonstrate significative difference and fermented between 8 and 10 days. Viniflora Oenos completed the

${ }^{1}$ Parte da Dissertação de Mestrado apresentada pelo primeiro autor ao Curso de Pós-graduação em Ciência e Tecnologia dos Alimentos, Universidade Federal de Santa Maria (UFSM).

${ }^{2}$ Farmacêutica Bioquímica, Mestre, Departamento de Tecnologia e Ciência dos Alimentos, UFSM, 97119-900, Santa Maria, RS. Autor para correspondência.

${ }^{3}$ Engenheiro Agrônomo, PhD, Professor Titular, Departamento de Ciência e Tecnologia dos Alimentos, UFSM. 
malolactic fermentation in less time. This demonstrates that the inoculation can be made before the end of alcoholic fermentation with good results. In the majority of the treatments there was not significative difference in the acetic acid production between the culture and the control. The behavior of the malic, acetic, lactic, piruvic and tartaric acids were showed.

Key words: Lactic culture, Leuconostoc oenos, must, organic acids, starter, wine.

\section{INTRODUÇÃO}

A fermentação maloláctica (FML) diminui a acidez total, muitas vezes elevada em vinhos tintos jovens do Estado do Rio Grande do Sul, e ocasiona ao mesmo tempo maior estabilidade biológica e complexidade no aroma e sabor. Os estudos de indução da FML em vinhos por inoculação bacteriana desenvolveram-se a partir da década de 60 , os quais levaram ao surgimento de diversas cepas comerciais de bactérias lácticas e revelaram fatores importantes que afetam a habilidade da bactéria crescer e conduzir esta fermentação (DAVIS et al., 1985). Alguns problemas foram constatados com o uso dessa prática, entre os quais a perda de viabilidade das bactérias lácticas (KUNKEE, 1974).

Estudos foram realizados com a inoculação de culturas lácticas em diferentes estádios de vinificação, mas nem sempre foi obtido sucesso. $\mathrm{Na}$ realidade, o momento ideal para a inoculação depende de vários fatores, como a composição do mosto, a cepa de levedura e as técnicas de elaboração (DAVIS $\boldsymbol{e t}$ al., 1985). A seleção de cepas de bactérias lácticas que degradam o ácido málico levou ao desenvolvimento de estudos de classificação e metabolismo deste grupo de bactérias em diversas regiões vitícolas (KUNKEE, 1967; GARVIE \& FARROW, 1980; WIBOWO et al., 1985; TRACEY \& BRITZ, 1987; PILONE et al., 1991; VAN VUUREN \& DICKS, 1993). Ainda hoje, muitas dúvidas existem sobre estes aspectos. $\mathrm{O}$ crescente desenvolvimento de métodos em cromatografia líquida de alta eficiência tem tornado mais fácil e precisa a dosagem de compostos envolvidos no metabolismo fermentativo de microrganismos.

A execução deste trabalho teve como objetivo observar o comportamento da cultura de Leuconostoc oenos, Viniflora Oenos, na indução da FML, em relação as bactérias nativas dos vinhos que não foram inoculados; determinar o momento ideal de indução e a influência sobre o andamento da fermentação alcoólica; observar o metabolismo de alguns ácidos orgânicos durante a FML.

\section{MATERIAIS E MÉTODOS}

Uvas da cv. Cabernet Sauvignon oriundas de Garibaldi, RS, da safra de 1993, foram esmagadas e desengaçadas. A composição do mosto obtido é apresentada na Tabela 1. Após a adição de $30 \mathrm{mg} / \mathrm{l}$ de SO e a correção de açúcar para 22 ?Brix, foi realizada a ådição de pé-de-cuba (2\%) usando a levedura Saccharomyces cerevisiae 20B isolada no Centro Nacional de Pesquisa de Uva e Vinho (EMBRAPA).

Foram feitas duas remontagens ao dia, durante quatro dias. Quando o mosto se apresentou em cada um dos seguintes estádios de fermentação, 34,1; 13,$8 ; 1,7$ e 1,5g/l de açúcar residual, quatro alíquotas (2,5 - 2,8 litros) foram separadas e duas delas foram inoculadas com a cultura comercial de Leuconostoc oenos, Viniflora Oenos (CHR HANSEN Ind. e Com. Ltda.). Esta, sob a forma liofilizada e contendo aproxima-damente $5 \times 10^{11}$ células viáveis por grama, foi inoculada diretamente no vinho na concentração de 20g/25001, conforme instruções do fabricante. As outras duas alíquotas não sofreram inoculação e serviram como controle. Para o último estádio $(1,5 \mathrm{~g} / \mathrm{l})$, o vinho foi separado da borra, através de trasfega, sete dias após o final da fermentação alcoólica. A descuba foi realizada no momento do primeiro estádio $(34,1 \mathrm{~g} / \mathrm{l})$. Todas as alíquotas (tratamentos) foram mantidas em recipientes de vidro, tampados com rolhas de borracha com sistema de saída para o $\mathrm{CO}_{2}$.

Açúcares redutores foram determinados pelo método de Fehling Causse Bonans, acidez total por titulometria, álcool por destilação e ebuliometria, pH pelo método eletrométrico. A degradação do ácido málico foi acompanhada a cada 2 ou 3 dias, por cromatografia em papel (RIBÉREAU-GAYON et al., 1980). Do mesmo modo, foram retiradas amostras e congeladas para análise quantitativa dos ácidos orgânicos individuais.

Foi utilizado um esquema fatorial tipo $2 \mathrm{x}$ 4 com delineamento experimental inteiramente casualizado, com duas repetições, em função dos fatores cultura maloláctica e estádios de inoculação, respectivamente. As médias dos números de dias e do ácido acético presente durante a FML, foram comparadas pelo teste de Tuckey em nível de 5\% de probabilidade.

Os ácidos tartárico, pirúvico, málico, láctico e acético foram separados e quantificados através de cromatografia líquida de alta eficiência (CLAE). Todos os reagentes apresentaram grau analítico e as soluções foram preparadas com água ultrapura, qualidade Milli-Q. 
A preparação das amostras consistiu dos seguintes procedimentos: descongelamento em banho de água quente (em torno de $50^{\circ} \mathrm{C}$ ), agitação manual, centrifugação a 2000rpm durante 15 minutos, banho de ultra-som durante 5 minutos, filtração com filtro de membrana $0,45 \mu \mathrm{m}$ e corrida através de uma coluna Adsorbex RP-8 (400mg) (E. Merck), para a eliminação das antocianinas.

O método cromatográfico foi desenvolvido num sistema modular VARIAN, equipado com bomba modelo $n .^{\circ} 5050$, detector UV/VIS modelo n. ${ }^{\circ} 5100$, injetor tipo Reodyne, integrador modelo n. ${ }^{\circ} 4290$, coluna de guarda $\left(\mathrm{C}_{18}, 5 \mu \mathrm{m}\right)$ modelo $\mathrm{C}-135 \mathrm{~B}$ e coluna Bondesil $\mathrm{C}_{18}(250 \mathrm{x} 4,6 \mathrm{~mm}$ i.d., tamanho da partícula $=5 \mu \mathrm{m})$.

As condições cromatográficas foram: solução de fosfato monopotássico $\left(\mathrm{KH}_{2} \mathrm{PO}_{4}\right) 0,2 \mathrm{M}$, levado a pH 2,4 com ácido fosfórico a $10 \%$, como fase móvel; Temperatura ambiente; fluxo de 1,0ml/ min.; absorbância a 210nm. e sensibilidade do detector de 0,08AUFS. Para a validação do método, cada ácido foi identificado pelo seu tempo de retenção $\left(t_{R}\right)$ em comparação com as soluções padrões de compostos puros e, pelo aumento da área do pico com a adição de cada ácido sobre uma amostra. A quantificação dos ácidos foi realizada pelo método do padrão externo, utilizando soluções padrões que consistiram da mistura dos ácidos em cinco concentrações diferentes. Este método apresentou problemas de resolução para o ácido láctico. Somente sob temperaturas mais altas e fluxo baixo foi possível a separação deste ácido, portanto não foi possível acompanhá-lo durante a FML. Análises de regressão linear simples foram utilizadas para relacionar os níveis de alguns ácidos orgânicos durante a FML.

\section{RESULTADOS DISCUSSÃO}

A degradação do ácido málico foi completa em todos os tratamentos. Houve uma redução de $37,35 \%$ de ácido málico durante a fermentação alcoólica (Tabela 1) sendo o restante totalmente metabolizado durante a FML (Figura 1).
Tabela I - Características químicas $\mathbf{c}$ valores dos ácidos orgainicos presentes no mosto e no vinho, nos estádios $(34,1-13,8$ 1.7 × $1.5 \mathrm{~g} / 1$ de ą̧úcar residual) da vinificaçăo $\mathrm{em}$ que a cultura foi inoculada.

\begin{tabular}{|c|c|c|c|c|c|}
\hline \multirow[t]{2}{*}{ Anàlises } & \multirow[t]{2}{*}{ Mosto } & \multicolumn{4}{|c|}{$\begin{array}{l}\text { Estidios de inoediajajo } \\
\text { (g/ de açucar redutor) }\end{array}$} \\
\hline & & 34.10 & 13.80 & 1,70 & 1.50 \\
\hline 'Brix & 18.50 & 5.00 & 1.60 & -0.90 & -1.20 \\
\hline Acidez total ( $\left.g^{\prime} /\right)$ & 10.95 & 9.75 & 10.00 & 8.17 & 8.02 \\
\hline Álcool (Cil.) & - & 10.90 & 12,10 & 12.30 & 12.30 \\
\hline $\mathrm{pH}$ & 3,19 & 3.49 & 3.44 & 3.42 & 3.51 \\
\hline Ácido tartárico (g/) & 3,80 & 3,40 & 3.60 & 3,94 & 4,22 \\
\hline Ácido pirityico (mgl) & 254.75 & 155.88 & 130.24 & 83.78 & 42.30 \\
\hline Ácido málico (g/1) & 5,97 & 4.91 & 4,54 & 3,74 & 3.59 \\
\hline Ácido acético (mgil) & 192.10 & 134,25 & 152.55 & 174,94 & 204,68 \\
\hline
\end{tabular}

Os valores de $\mathrm{pH}$ no momento da inoculação (Tabela 1) se apresentaram numa faixa considerada ideal para o desenvolvimento das bactérias lácticas, o que pode explicar em parte o grau de incidência da FML. Como Cabernet Sauvignon é uma cultivar tinta, sua vinificação compreende o contato com a película, o que é de grande importância para o desenvolvimento das bactérias lácticas.

Nos dados apresentados na Tabela 2, observa-se que a cultura completou a FML mais

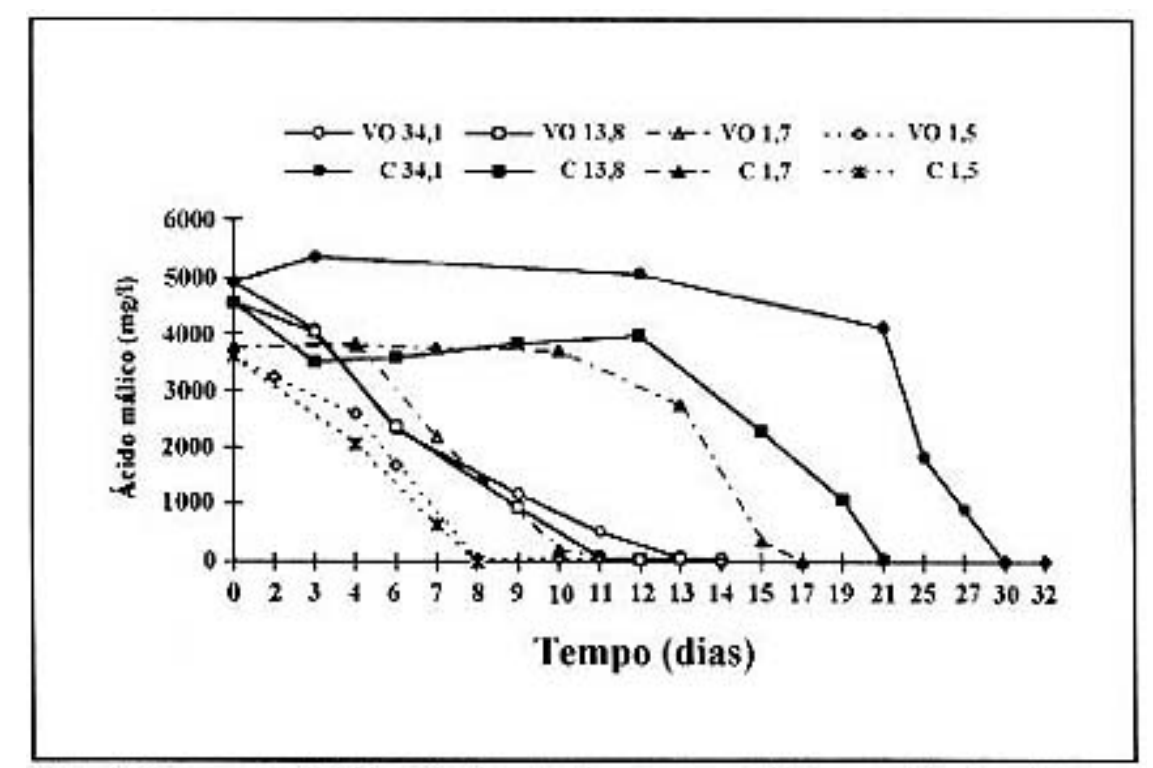

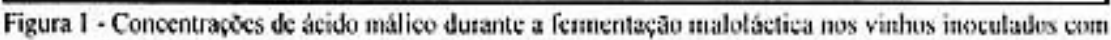
a cultura Viniflora Qenos (VO) e nos controles (C). nos estádios de inoculaçđơo (34.1: $13.8: 1.7$ e I.5gil de açúcar),

Ciência Rural, v. 27, n. 2, 1997. 
rapidamente nos dois primeiros estádios (34,1 e 13,8g/ 1). Não houve diferença significativa entre a cultura e o controle nos estádios posteriores. Isto indica que a cultura foi mais resistente às condições do vinho, durante a fermentação alcoólica.

\begin{tabular}{|c|c|c|c|c|c|}
\hline \multirow[t]{2}{*}{ Período } & \multirow[t]{2}{*}{ Cultura } & \multicolumn{4}{|c|}{ Estádios de inoculação (g/l de açúcar) } \\
\hline & & 34,10 & 13,80 & 1,70 & 1,50 \\
\hline 1 & $\begin{array}{l}\text { Controle } \\
\text { Viniflora Oenos }\end{array}$ & $\begin{array}{l}28,5 \mathrm{a}^{*} \\
14,0 \mathrm{~cd}\end{array}$ & $\begin{array}{l}20,5 \mathrm{~b} \\
13,0 \text { cde }\end{array}$ & $\begin{array}{l}16,5 \mathrm{bc} \\
11,0 \mathrm{cde}\end{array}$ & $\begin{array}{ll}8,0 & \text { e } \\
9,5 & \text { de }\end{array}$ \\
\hline 2 & $\begin{array}{l}\text { Controle } \\
\text { Viniflora Oenos }\end{array}$ & $\begin{array}{l}31,5 \mathrm{a} \\
17,0 \mathrm{c}\end{array}$ & $\begin{array}{l}24,5 \mathrm{~b} \\
17,0 \mathrm{c}\end{array}$ & $\begin{array}{l}24,5 \mathrm{~b} \\
19,0 \mathrm{bc}\end{array}$ & $\begin{array}{l}23,0 \mathrm{~b} \\
24,5 \mathrm{~b}\end{array}$ \\
\hline
\end{tabular}

Nos estádios mais próximos do final da fermentação alcoólica, menos tempo foi necessário para completar a FML nos controles, sendo que entre o segundo e terceiro estádios não houve diferença significativa. Com a cultura o efeito da inoculação nos diferentes estádios não foi muito acentuado, não havendo diferença significativa entre os estádios. A trasfega realizada no vinho, no último estádio de inoculação, não parece ter interferido negativamente sobre a ocorrência e velocidade da FML, mesmo que pouca quantidade de borra tenha sido separada; ao contrário, a FML ocorreu mais rapidamente, o que coincide com resultados citados por Marques Gomes et al. apud MENEZES et al. (1976). Este resultado evidencia que nas condições apresentadas pelo vinho desta cultivar não seria necessário deixar o vinho sobre as borras para a realização da FML, o que evitaria o risco da produção de aromas indesejáveis.

Observou-se que nos controles, com exceção do último estádio, a FML iniciou entre 10 e 13 dias aproximadamente após a separação das alíquotas nos respectivos estádios (Figura 1). Este fato demonstra que as bactérias nativas desenvolveram-se somente uma semana, aproximadamente, após o término da fermentação alcoólica. É conhecido que as bactérias lácticas selvagens crescem naturalmente e conduzem a FML após a fermentação alcoólica ter ocorrido.
Certamente fatores como o $\mathrm{pH}$, o anidrido sulfuroso, a atividade das leveduras e o nível de aminoácidos liberados pelas leveduras depositadas, propiciam a formação de um ambiente seletivo. O teor alcoólico teria efeito contrário ao crescimento das bactérias, já que em estádios mais tardios seus valores são mais elevados. Mas, neste estudo, ao contrário, parece fazer parte deste ambiente seletivo.

Evidenciou-se que a indução da FML antes do final da fermentação alcoólica ( 5 Brix) é uma prática vantajosa em relação ao tempo, o que é demonstrado pela fermentação com a cultura Viniflora Oenos. O período entre a adição do péde-cuba com a levedura 20B e a obtenção de um vinho pronto para a clarificação, também é demonstrado na Tabela 2. Com a cultura foi possível finalizar as duas fermentações em 17 dias nos dois primeiros estádios de inoculação $(34,1 \mathrm{e}$ $13,8 \mathrm{~g} / \mathrm{l})$. Além do ganho em tempo há vantagens como a segurança e o controle da fermentação. Nos dois últimos estádios de inoculação $(1,7$ e $1,5 \mathrm{~g} / \mathrm{l})$ não houveram diferenças significativas entre a cultura e o controle, mas permanecem as outras vantagens em favor da cultura.

Os resultados de ácido láctico ao final da FML de todos os tratamentos (bactéria x estádio) não apresentaram interação entre as variáveis, estádios e bactérias, em nível de $5 \%$ de probabilidade. As médias de ácido láctico, considerando todos os estádios, foram de $3,19 \mathrm{~g} / 1$ para o controle e, $3,18 \mathrm{~g} / 1$ para a cultura. Nos estádios 34,1; 13,8; 1,7 e 1,5g/l, as médias foram de 3,$52 ; 2,93 ; 3,39$ e $2,89 \mathrm{~g} / 1$, respectivamente.

Por outro lado, não houve diferença entre as médias de ácido acético produzido pela cultura pura e no controle durante a fermentação alcoólica e maloláctica (Tabela 3). Somente no segundo estádio inoculado com a cultura, a produção de ácido acético foi superior ao controle. A cultura apresentou as maiores médias, de 553,54 e 496,58mg/l, no segundo e último estádio.

Sabe-se que bactérias lácticas heterofermentativas metabolizam açúcares com formação de ácido acético, entre outros produtos finais (KANDLER, 1983). Alguns autores apontam que a inoculação de bactérias lácticas no mosto em fermentação, quando açúcares ainda estão presentes, pode provocar uma formação adicional de ácido acético e, neste caso, desaconselham o uso de espécies heterofermentativas. Com base nas médias de ácido acético para a cultura Viniflora Oenos pode-se observar que no estádio com maior açúcar residual não foi demonstrada a maior produção de ácido acético durante a FML. Da mesma forma, os 
Tabela 3 - Médias das concentrações de ácido acético (mg/t) durante a fermentaçå naloláctica em todos os tratanentos.

\begin{tabular}{|c|c|c|c|c|c|}
\hline \multirow[b]{2}{*}{ Culiuras } & \multicolumn{4}{|c|}{ Estädios de inoculaçđ̃o (g/ de açu̇car) } & \multirow[b]{2}{*}{ Mćdias } \\
\hline & 34.10 & 13.80 & 1.70 & 1,50 & \\
\hline Canirole & 265,16 cd & $199.20 \mathrm{~d}$ & $287.11 \mathrm{bcd}$ & $468.50 \mathrm{abc}$ & $300,08 \mathrm{~B}$ \\
\hline Viniffora Oenos & 246.17 od & $553,54 \mathrm{a}$ & 273,82 bod & $496,58 \mathrm{ab}$ & $408.65 A$ \\
\hline Médias & $253.02 \mathrm{C}$ & $358.65 \mathrm{~B}$ & $282,(18 \mathrm{BC}$ & $483,21 \mathrm{~A}$ & . \\
\hline
\end{tabular}

"Médias nåo seguadas por mesma letra minúscula ou por mesma letra maiúsçula diferem pelo teste de Tuckey em nivel de $5 \%$ de probabilidade.

teores alcoólicos de 12,3 a $12,6^{\circ} \mathrm{GL}$ e de açúcares redutores de 1,28 a 1,52g/l, determinados ao final da FML indicam que não houve parada da fermentação alcoólica e que as bactérias não se utilizaram dos açúcares residuais. Esses dados concordam com aqueles obtidos por PEYNAUD (1984) de que, sob condições de baixo pH, as bactérias da FML são capazes de atacar o ácido málico sem tocar no açúcar, formando pouco ácido acético. As bactérias que causam deterioração, pelo contrário, desenvolvem-se em meios menos ácidos, atacam com mais facilidade os açúcares e elevam a acidez volátil.

Algumas bactérias lácticas metabolizam oácido cítrico durante a FML, com formação de ácido acético entre diversos produtos finais. Segundo WIBOWO et al. (1985) esse metabolismo também foi observado em Leuconostoc oenos, embora apenas em algumas cepas. Na verdade, pouco é conhecido sobre a produção de acetato por $\boldsymbol{L}$. oenos (GARCÍA et al., 1992; VAN VUUREN \& DICKS, 1993).

Algumas bactérias lácticas metabolizam o ácido cítrico durante a FML, com formação de ácido acético entre diversos produtos finais. Segundo WIBOWO et al. (1985) esse metabolismo também foi observado em Leuconostoc oenos, embora apenas em algumas cepas. $\mathrm{Na}$ verdade, pouco é conhecido sobre a produção de acetato por $\boldsymbol{L}$. oenos (GARCÍA et al., 1992; VAN VUUREN \& DICKS, 1993).

O grau de dependência entre a formação de ácido acético e o processo de FML, indicaram que na maioria dos tratamentos o relacionamento, entre as concentrações de ácido málico e acético durante a FML, foi significativo, existindo um grau de associação de médio a alto entre os dados. Os coeficientes de regressão indicam que uma faixa de 3,03\% (y = $\left.0,0303 \mathrm{x}+326,46, \mathrm{r}^{2}=0,8470\right)$ a $13,24 \%$ $\left(\mathrm{y}=-0,1324 \mathrm{x}+597,74, \mathrm{r}^{2}=0,4428\right) \mathrm{de}$ ácido acético (y) foi produzido em relação a quantidade de ácido málico degradado (x). A média entre os tratamentos que apresentaram relacionamento significativo foi de $8,47 \%$, para a cultura e $6,84 \%$, para o controle. Entre os estádios, os menores coeficientes de regressão foram observados no estádio com $1,7 \mathrm{~g} / 1$ de açúcar residual. É claro que estes valores variam dependendo do nível de ácido cítrico presente no vinho, e do metabolismo deste ácido pelas bactérias lácticas.

Os valores de ácido pirúvico diminuíram ao se aproximar o final da fermentação alcoólica e durante a FML, chegando a valores de 0 a $32 \mathrm{mg} / 1$. Nos dois últimos estádios de inoculação não foi possível detectar o pico deste ácido, o que sugere sua ausência nestes estádios.

As médias de ácido tartárico durante a FML, considerando todos os estádios, foram de 2,95 g/l para o controle e, 2,86g/l para a cultura. Não houve interação entre as variáveis, estádios e bactérias, em nível de 5\% de probabilidade, e também não houve relacionamento com os valores de ácido málico durante a FML.

As médias de acidez total e $\mathrm{pH}$ ao término da FML são demonstradas na Tabela 4. Considerando os valores de acidez total no momento da inoculação nos dois últimos estádios, ou seja, após o término da fermentação alcoólica, pôde-se observar reduções de 1,30 e $1,15 \mathrm{~g} / 1$ na acidez total e aumentos de 0,29 e

Tabela 4 - Acidez total (g/) e pH nos vinhos após a FML.

\begin{tabular}{|c|c|c|c|c|c|c|}
\hline \multirow[b]{2}{*}{ Culturas } & \multirow[b]{2}{*}{ Variáveis } & \multicolumn{4}{|c|}{$\begin{array}{l}\text { Estàgios de inoculaçâo } \\
\text { (g/l de açucar) }\end{array}$} & \multirow[b]{2}{*}{ Médias } \\
\hline & & 34,10 & 13,80 & 1.70 & 1.50 & \\
\hline \multirow[t]{2}{*}{ Viniflora Oenos } & Acidez total & 6.56 & 6.52 & 6.78 & 6.89 & 6,60 \\
\hline & $\mathrm{pH}$ & 3,70 & 3.74 & 3,70 & 3,77 & 3,72 \\
\hline \multirow[t]{2}{*}{ Controle } & Acidez total & 6,89 & 6.90 & 6,97 & 6,86 & 6,90 \\
\hline & $\mathrm{pH}$ & 3,69 & 3.76 & 3,72 & 3,75 & 3,73 \\
\hline \multirow[t]{2}{*}{ Médias } & Acidez total & 6,72 & 6.71 & 6.87 & 6,87 & - \\
\hline & $\mathrm{pH}$ & 3,69 & 3.75 & 3,71 & 3,76 & - \\
\hline
\end{tabular}


0,25 nos valores de $\mathrm{pH}$, causados pela FML. Estes dados conferem com a literatura, onde é previsto reduções na acidez total de $1 \mathrm{a} 3 \mathrm{~g} / \mathrm{l}$ e aumentos no $\mathrm{pH}$ de 0,1 a 0,3 .

\section{CONCLUSÃO}

A indução da fermentação maloláctica utilizando a inoculação da cultura Viniflora Oenos, antes do término da fermentação alcoólica, demonstra ser uma prática viável e vantajosa em relação a incidência e ao tempo requerido. Os vinhos produzidos com a utilização da cultura Viniflora Oenos não apresentam valores elevados de ácido acético.

\section{AGRADECIMENTOS}

Agradecemos a vinícola Maison Forestier, ao CNPUV-EMBRAPA e a HA-LA do Brasil pelo apoio prestado.

\section{REFERÊNCIAS BIBLIOGRÁFICAS}

DAVIS, C.R., WIBOWO, D., ESCHENBRUCH, R. et al. Practical implications of malolactic fermentation: A review. American Journal of Enology and Viticulture, Davis, v. 36, n. 4, p. 290-301, 1985.

GARCÍA, M.J., ZÚÑIGA, M., URUBURU, F. Revisión: El metabolismo y el control de las bacterias lácticas en el vino. Revista Española de Ciencia y Tecnología de Alimentos, v. 32, n. 3, p. 233-268, 1992.

GARVIE, E.I., FARROW, J.A.E. The differentiation of Leuconostoc oenos from non-acidophilic species of Leuconostoc, and the identification of five strains from the american type culture colletion. American Journal of Enology and Viticulture, Davis, v. 31, n. 2, p. 154-157, 1980.
KANDLER, O. Carbohydrate metabolism in lactic acid bacteria. Antonie van Leeuwenhoek, Wageningen, v. 49, p. 209-224, 1983.

KUNKEE, R.E. Malo-lactic fermentation and winemaking. In: DRAWERT, F. Chemistry of winemaking. Washington: American Chemical Society, 1974. Cap. 7, p. 151-170. (Advances in Chemistry, 137).

KUNKEE, R.E. Malo-lactic fermentation. Adv Appl Microbiol, v. 9, p. 235-279, 1967.

MENEZES, T.J.B., HASHIZUME, T., LIMA, U.A. Fermentação maloláctica natural e induzida em vinhos. Coletânea do Instituto de Tecnologia de Alimentos, Campinas, v. 7, p. 467-484, 1976.

PEYNAUD, E. Enología práctica: Conocimiento y elaboracion del "vino". 2. ed. Madrid: Ediciones Mundi-Prensa, 1984. 405 p.

PILONE, G.J., CLAYTON, M.G., VAN DUIVENBODEN, R.J. Characterization of wine lactic acid bacteria: Single broth culture for tests of heterofermentation, mannitol from fructose, and ammonia from arginine. American Journal of Enology and Viticulture, Davis, v. 42, n. 2, p. 153-157, 1991.

RIBÉREAU-GAYON, J., PEYNAUD, E., SUDRAUD, P., et al. Tratado de enologia. Ciencias y tecnicas del vino. Buenos Aires: Hemisferio Sur, 1980. 671 p.

TRACEY, R.P., BRITZ, T.J. A numerical taxonomic study of Leuconostoc oenos strains from wine. Journal of Applied Bacteriology, Oxford, v. 63, p. 523-532, 1987.

VAN VUUREN, H.J.J., DICKS, M.T. Leuconostoc oenos: A review. American Journal of Enology and Viticulture, Davis, v. 44, n. 1, p. 99-112, 1993.

WIBOWO, D., ESCHENBRUCH, R., DAVIS, C.R. $\boldsymbol{e}$ t al. Occurrence and growth of lactic acid bacteria in wine: A review. American Journal of Enology and Viticulture, Davis, v. 36, n. 4, p. 302-313, 1985. 